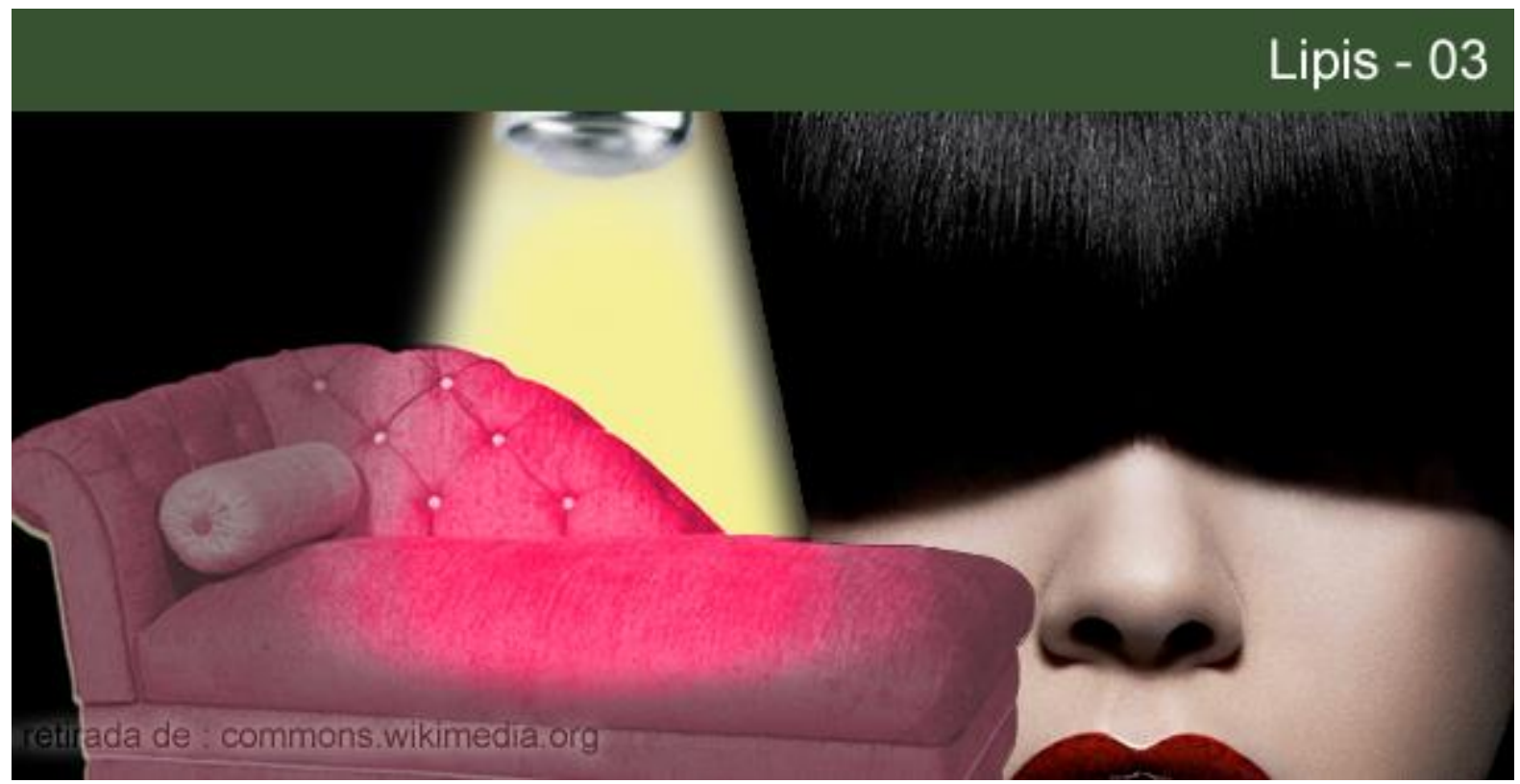

\title{
DA PERVERSÃO NOSSA DE CADA DIA ÀS GRANDES PERVERSÕES DO SEXUAL ${ }^{1}$
}

\section{Paulo Roberto Ceccarelli}

Psicólogo; Psicanalista; Doutor em Psicopatologia Fundamental e Psicanálise e Pós-doutor pela Universidade de Paris VII. Membro da Associação Universitária de Pesquisa em Psicopatologia Fundamental; sócio do Círculo Psicanalítico de Minas Gerais; membro da Société de Psychanalyse Freudienne, Paris, França; membro fundador da Rede Internacional em Psicopatologia Transcultural. Professor da Pontifícia Universidade Católica-MG. Professor credenciado a dirigir pesquisas, e docente no Programa de Pós-Graduação em Psicologia/UFPA. Orientador de Pesquisa e Professor do Mestrado Profissional de Promoção de Saúde e Prevenção da Violência da Faculdade de Medicina da UFMG. Pesquisador Associado do LIPIS (PUC$R J$ ). Diretor científico do Centro de Atenção à Saúde Mental - CESAME (www.cesamebh.com.br); Pesquisador do CNPq.E-mail: paulorcbh@mac.com.

Resumo: A partir do sexual freudiano, o texto aborda a questão da perversão dentro da perspectiva freudiana no trabalho de cultura (Kulturarbeit). Para Freud, uma das maneiras de se entender as perversões leva em conta a não "domesticação" das pulsões pelo trabalho da cultura. Nessa perspectiva, discutir-se-á as potencialidades de perversão, da perversão nossa de cada dia às grandes perversões do sexual passando pela perversão do outro lado do divã, assim como a posição do analista na escuta das perversões.

Palavras-chave: Trabalho de cultura. Pulsão. Destinos pulsionais. Perversões.

\section{FROM OUR DAILY PERVERSION TO THE GREAT PERVERSIONS OF THE SEXUAL}

Abstract: In this work, the author discusses, starting form Freud's description of the sexual, perversion from the Freudian perspective of the work of culture (Kulturarbeit). For Freud, one of the ways to understand perversion takes into account the non "domestication" of the drives by the work of culture. In this perspective, the potential to perversions will be discussed from our dailyperversion, to the great perversions of the sexual, including the perversion on the other side of the couch. Also, same considerations of the position of the analyst when hearing to perversions will be brought upon.

\footnotetext{
${ }^{1}$ Este texto faz parte de um projeto de pesquisa que conta com uma Bolsa de Produtividade em Pesquisa do CNPq (processo $n^{\text {o: }}$ 312687/2013-3).
}

\section{POLÊM!CA | Revista Eletronica da Ueji}


Keywords: Work of culture. Drive. Drives destiny. Perversions.

O que descrevemos como o "caráter" de uma pessoa é construído em grande parte com o material de excitações sexuais, e se compõe de pulsões fixadas desde a infância, de construções alcançadas por meio da sublimação, e de outras construções, empregadas para eficazmente conter os impulsos perversos que foram reconhecidos como inutilizáveis."

Freud, 1905.

\section{Introdução}

Inicialmente, gostaria de chamar a atenção para o uso da palavra sexual no título deste trabalho. O texto de referência de Freud escrito em 1905 sobre esse tema, o famoso Drei Abhandlungen zur Sexualtheorie foi traduzido em português por Três Ensaios sobre a teoria da sexualidade. Entretanto, trata-se de Três Ensaios sobre a teoria sexual. Ao longo de sua obra, Freud interessou-se pelo sexual, isto é, pelo pulsional que escapa a qualquer apreensão direta, propondo uma teoria sobre suas origens, seus destinos, seus entraves. Como sabemos, as posições inovadoras e revolucionárias de Freud só foram possíveis graças à descoberta do sexual infantil que busca prazeres perversos, inusitados e polimorfos, nos quais o aspecto reprodutivo está ausente. É justamente sobre esse sexual bruto que o trabalho de cultura, como pretendemos mostrar, incide, transformando-o, via sublimação, em bens culturais e ideias, ou recalcando-o: quando estes expedientes falham, estamos frente a uma manifestação perversa do sexual ou, do retorno do recalcado, que se manifesta nos sintomas neuróticos. (Freud, 1908). Já a sexualidade, ou melhor, os discursos sobre a sexualidade, são construções historicamente datadas que variam segundo o momento sócio-político, e que traduzem tentativas, sempre fracassadas, de controle do sexual através da regulamentação das práticas sexuais (CECCARELLI \& SALLES, 2010).

Muito antes dos aportes freudianos para a compreensão dos elementos constitutivos do "caráter" de uma pessoa, as manifestações ditas "perversas" já haviam sido amplamente debatidas e catalogadas. A designação de perversão, ou sexualidade perversa, é tributária do discurso dominante que constrói a "norma sexual" a ser observada (FOUCAULT, 1984, 1985, 1985b). A perversão é um fenômeno trans-histórico, presente em todas as culturas. E, muitas vezes, designamos de perversos "aqueles que aceitam traduzir por seus atos estranhos as tendências inconfessáveis que nos habitam" (ROUDINESCO, 2007, p. 15). Entretanto, quando levamos em conta as relações entre as perversões e moral sexual de uma dada cultura,

\section{POLÊM!CA | Revista Eletronica da verj}


constatamos que uma definição exaustiva e universal do que deveria ser considerado "perversão" constitui um problema que está longe de ser elucidado. No âmbito da psicanálise, a definição do "fenômeno perverso" não encontra consenso entre os modelos teórico-clínicos que tentam caracterizá-lo, o que leva a diferentes propostas de escuta e de direção do tratamento.

Em trabalhos anteriores (CECCARELLI 2005, 2011; CECCARELLI \& SANTOS, 2010), tive a oportunidade de apresentar algumas considerações sobre as perversões sob diferentes abordagens. Nesse artigo, gostaria de avançar o debate a partir de um dos operadores que atravessa a obra freudiana: o trabalho de cultura (Kulturarbeit). Juntamente com o recalque orgânico (Freud, 1905, 1930), o trabalho de cultura é uma noção central para se compreender a origem do processo civilizatório. Na Conf. XXXI, A dissecação da personalidade psíquica, lemos:

Seu propósito [o da psicanálise] é, na verdade, fortalecer o ego, fazê-lo mais independente do superego, ampliar seu campo de percepção e expandir sua organização, de maneira a poder assenhorear-se de novas partes do id. Onde estava o id, ali estará o ego (Wo es war, soll ich werden). É uma obra de cultura (Kulturarbeit), - não diferente da drenagem do Zuider Zee. (FREUD, 1933a, p. 102). ${ }^{2}$

Da mesma forma que os conhecimentos adquiridos ao longo de anos, o trabalho de cultura permitiu que parte do Mar do Sul (Zuider Zee) fosse transformado em terras cultiváveis; as moções pulsionais inutilizáveis são transformadas, via sublimação, no "acervo cultural comum de bens materiais e ideais" (FREUD, 1908, p. 183): "grande parte das forças suscetíveis de utilização em atividades culturais (Kulturarbeit) são obtidas pela repressão (Unterdrückung) dos componentes perversos da excitação sexual” (FREUD, 1908, p. 194). Isto significa que os ideais culturais e as moções perversas são dois lados de uma mesma moeda; duas representações psíquicas para um mesmo quantum pulsional.

O trabalho de cultura, resultado da "coerção e da renúncia das pulsões" (Zwang und Triebverzicht) (FREUD, 1927, 17) ao longo milhares de anos, impõe limites à satisfação pulsional. Ele marca a gêneses da espécie humana (filogênese) a ser repetido por cada um de nós (ontogênese). É o que marca e diferencia a nossa espécie. A cultura "cria" o homem; não

\footnotetext{
${ }^{2} \mathrm{O}$ acréscimo do artigo o na Standard Edition - "Onde estava o id, ali estará $\mathbf{o}$ ego - muda totalmente o sentido do alemão. Wo Es war denuncia a condição de significante do sintoma, e revela a verdade até então desconhecida ao Eu (LACAN, 1966). Onde se era falado, o Eu assume sua herança - soll ich werden - tornandose sujeito; lá onde era Isso, Eu apareço.
} 
existe ser humano fora da cultura: recusar o trabalho de cultura é decretar a morte ontológica. Todavia, a grande dificuldade desse processo é que, em apenas alguns anos, a criança deverá "assimilar os resultados de uma evolução cultural que se estende por milhares de anos" (FREUD, 1933, 180). Os que malogram neste processo sofrem "as consequências do seu desvio dos padrões de civilização" (FREUD, 1908, 196).

Graças ao trabalho da cultura vivemos no que chamamos da civilização (ou cultura) ${ }^{3}$ : uma dinâmica pulsional que nos permite, por um lado, conhecer e controlar as forças da natureza utilizando-as a nosso favor e, por outro lado, regulamentar as relações entre os homens no que diz respeito à distribuição das riquezas disponíveis, às modalidades de satisfação pulsional aceitas, e o controle da agressividade (FREUD, 1927).

Tenho por hipótese que o surgimento de uma perversão - desde uma posição subjetiva até a dimensão social, passando pela prática clínica - pode ser entendida como uma falha, uma impossibilidade de ação, do trabalho de cultura. Nesse caso, a perversão seria o resultado da não realização, ou da não internalização deste trabalho.

\title{
O recalque orgânico
}

Um dos pontos fortes do trabalho de cultura diz respeito ao recalque orgânico. Nas cartas a Fliess de 11/01/1887 (MASSON, 1986, p. 222) e de 14/11/1887 (MASSON, 1986, p. 280), Freud faz um paralelo entre a perversão e a ausência do "recalcamento sexual orgânico". E no texto de 1906, Meus pontos de vista sobre o papel desempenhado pela sexualidade na etiologia das neuroses, essa expressão aparece pela primeira vez:

\begin{abstract}
Considero valioso enfatizar que, em minhas concepções sobre a etiologia das psiconeuroses, a despeito de todas as modificações, houve dois pontos de vista que nunca reneguei ou abandonei: a importância da sexualidade e do infantilismo. Afora isso, em lugar das influências acidentais coloquei fatores constitucionais, e a "defesa", no sentido puramente psicológico, foi substituída pelo "recalcamento sexual” orgânico. (FREUD, 1906, p. 290).
\end{abstract}

Importantes aquisições culturais, o sentimento de vergonha, de asco, assim como a construção dos ideais morais e estéticos da civilização são "organicamente condicionados e fixados pela hereditariedade" sem a participação da educação (FREUD, 1905, p. 181). "O desenvolvimento cultural é comparável a um processo orgânico", escreve Freud em sua

\footnotetext{
${ }^{3}$ Para Freud, a civilização humana representa "tudo aquilo em que a vida humana se elevou acima de sua condição animal e difere da vida dos animais (...) e desprezo ter que distinguir entre cultura e civilização" (FREUD, 1927, p. 16).
}

\section{POLÊM!CA | Revista Eetroronica da veri}


conferência sobre A questão de uma Weltanschauung (FREUD, 1933b, p. 217). E na carta a Einstein, lemos:

\begin{abstract}
ainda não nos familiarizamos com a idéia de que a evolução da civilização é um processo orgânico desta ordem. As modificações psíquicas que acompanham o processo de civilização são notórias e inequívocas. Consistem num progressivo deslocamento dos fins pulsionais e numa limitação imposta aos impulsos pulsionais. Sensações que para os nossos ancestrais eram agradáveis, tornaram-se indiferentes ou até mesmo intoleráveis para nós; há motivos orgânicos para as modificações em nossos ideais éticos e estéticos. (FREUD, 1933c, p. 258).
\end{abstract}

Em uma nota de rodapé no famoso Mal-estar na civilização, Freud (1930, 119 e seg.) faz importantes considerações sobre o recalque orgânico que merecem ser debatidas de forma mais detida. Por exemplo, a substituição das sensações prazerosas olfativas pela excitação visual, quando da aquisição da posição bípede. É dentro dessa perspectiva, que ChasseguetSmirgel (1987) trabalha a hipótese segundo a qual devido ao abandono de uma forma de gratificação, essa se torna idealizada transformando o perverso em um grande esteta.

\title{
O trabalho de cultura (Kulturarbeit)
}

Três textos de Freud, em particular, balizarão minhas reflexões: Neurose de transferência: uma síntese (1915a), Moral sexual civilizada e doença nervosa moderna (1908) e Reflexões para os tempos de guerra e morte (1915b).

Em Neurose de transferência: uma síntese (FREUD, 1915a), encontramos de forma sistematizada as considerações freudianas sobre as origens do trabalho de cultura. Uma catástrofe ecológica de proporções avassaladoras obrigou o ancestral do homem a fazer profundas reorganizações psíquicas para enfrentar o excesso externo - as transformações do meio-ambiente - e o interno - as demandas pulsionais - cujas satisfações se viram ameaçadas.

Esta evolução, no sentido darwiniano, garantiu a sobrevivência fazendo com que a energia psíquica procurasse novos modos de satisfação - novos destinos para a Trieb (FREUD, 1915c) - pois os objetos de satisfação "tradicionais" começaram a faltar. A Trieb passou a prescindir de um objeto fixo de satisfação biologicamente determinado, e a utilizarse de qualquer objeto. A única "exigência" é que o objeto satisfizesse "as tensões causadas pelas necessidades do Id" (FREUD, 1938, p. 173), mantendo o nível de tensão o mais baixo possível. Manter o nível de tensão o mais baixo possível, passa a ser a condição de satisfação da energia psíquica (as formas de prazer) e não mais a reprodução.

\section{POLÊM!CA | Revista Eletronica da Ueji}


A partir daí, Freud (1915a) traça o trajeto de "domesticação" das pulsões, via trabalho de cultura. Como já dissemos, cada etapa do desenvolvimento (filogênese), do mito da era glacial (FREUD, 1915) ao mito fundador da cultura, Totem e Tabu (FREUD, 1913), seria repetida por cada um de nós, do nascimento ao complexo de Édipo.

Ainda em Neurose de transferência: uma síntese, Freud (1915a) compreende as neuroses, as perversões e as psicoses (neuroses narcísicas) como entraves nos caminhos pulsionais que comprometem o trabalho de cultura, e impedem que o indivíduo transforme, via sublimação, o quantum pulsional inutilizável em bens culturalmente valorizados.

Em Moral sexual civilizada e doença nervosa moderna (FREUD, 1908), lemos que a civilização só foi possível graças à repressão (Unterdrückung) das pulsões. E as aquisições culturais são o resultado, via sublimação, da capacidade de motilidade pulsional: é justamente aí que reside o seu valor para a civilização:

Cada indivíduo renuncia a uma parte dos seus atributos: a uma parcela do seu sentimento de onipotência ou ainda das inclinações vingativas ou agressivas de sua personalidade. Dessas contribuições resulta o acervo cultural comum de bens materiais e ideais. (FREUD, 1908, p. 192).

Entretanto,

\begin{abstract}
Aquele que em consequência de sua constituição indomável não consegue concordar com a repressão da pulsão (Triebunterdrückung), é visto pela sociedade como 'criminoso', um 'outlaw' - a menos que sua posição social ou suas capacidades excepcionais the permitam impor-se como um grande homem, como um 'herói' (Ibid. p. 192).
\end{abstract}

Quando a pulsão se fixa em um modo único e obstinado de satisfação, ela se torna inutilizável para o processo civilizatório podendo, inclusive, "degenerar-se até as chamadas anormalidades" (FREUD, 1908, p. 193) - as perversões.

Contudo, tanto o vigor da pulsão sexual (o seu quantum de energia) como a parcela da pulsão suscetível de sublimação variam de um indivíduo para outro. E o que determinará “qual parte da pulsão sexual será possível sublimar e utilizar" (FREUD, 1908, p. 193) é o constitucional. E existe um limite "além do qual suas constituições [das pessoas] não podem obedecer exigências da civilização" (FREUD, 1908, p. 197).

Daí, a conclusão lapidar de Freud:

Uma das óbvias injustiças sociais é que os padrões de civilização exigem de todos uma idêntica conduta sexual, conduta esta que pode ser observada sem dificuldades por alguns indivíduos, graças às suas organizações, mas que impõe a outros os mais 
pesados sacrifícios psíquicos. (Ibid. p. 197).

A desilusão de Freud em relação à eficácia do trabalho de cultura é patente no texto Reflexões para os tempos de guerra e morte (FREUD, 1915b). Em um verdadeiro desabafo, Freud renuncia à crença na capacidade da ciência em fornecer melhores condições de vida. Situações extremas - guerras, atos terroristas, governos totalitários - resultam da efração pulsional: Eros, o pai da civilização, perde sua capacidade de ligação, o que provoca a volta às condições primevas. A guerra, "a mais óbvia oposição às modificações pulsionais que o processo civilizatório (Kulturprozess) tanto demorou para nos incutir” (FREUD, 1933c, p. 258), destrói as aquisições culturais, levando ao rebaixamento dos padrões estéticos. O próximo passo é a regressão a um estado de barbárie que anula a diferença entre as nações civilizadas e povos "primitivos", assim como aquela entre os homens mais brilhantes e os neuróticos graves.

Tais constatações, que culminam no Além do princípio de prazer com a introdução da pulsão de morte (FREUD, 1920), leva Freud a rever suas hipóteses relativas à eficiência do trabalho de cultura. Se, por um lado, é inegável, como no caso do Zuider Zee, a presença do trabalho de cultura nos avanços tecnológicos e na produção de conhecimento, por outro lado, do ponto de vista do "progresso" psíquico, não fomos muito longe: ainda que se possa argumentar que as modalidade de sublimação tenham sofrido modificações com o passar dos milénios, as reivindicações narcísicas, os interesse individuais em detrimento dos grupais, alteram muito pouco, para não dizer que não alteraram em absoluto, desde a aurora da humanidade. $\mathrm{O}$ retorno do primitivo está sempre à porta quando nos sentimos ameaçados de perder nossos objetos de satisfação (FREUD, 1915b). O conservadorismo pulsional, a compulsão à repetição, faz de nossa história um eterno (re)começo.

Vemos, pelo que foi dito, que o surgimento do estado de cultura, uma astúcia evolutiva, só foi possível graças os novos destinos pulsionais introduzidos pela desvinculação da Trieb a um único objeto de satisfação. Por outro lado, este mesmo trabalho cobra um alto preço ao exigir a renúncia de certas formas de satisfação sexual para que a vida em comunidade seja possível. Isto significa que as exigências da civilização são incompatíveis com o sexual, fazendo com que a cultura seja geradora de mal-estar e não de felicidade: o mal-estar é a sexual, ou melhor, suas exigências de satisfação (FREUD, 1930).

Como escrevi em outro texto:

\section{POLÊM!CA | Revista Eletronica da veri}


O trabalho de cultura nada mais faz do que criar estratégias (aparentemente novas) de recalque e repressão que mascaram o mal-estar (Unbehagen) inerente à cultura. As demandas e as vicissitudes pulsionais - sobretudo o par amor/ódio - em nada alteraram com o passar dos milênios. (CECCARELLI, 2009, p. 38).

\section{Perversão e trabalho de cultura}

A leitura destes textos freudianos sugere que as manifestações perversas da sexualidade resultam de uma falha do trabalho de cultura, pelos motivos elencados por Freud, em afastar certos elementos do psiquismo, o que inclui o recalque orgânico, e, consequentemente transformá-los em algo culturalmente valorizado. Os indivíduos nos quais o trabalho de cultura não se efetivou são socialmente infelizes, mostrando que as exigências culturais "constituem uma fonte de sofrimentos para uma certa parcela da humanidade" (FREUD, 1908, p. 195).

Nosso aparelho psíquico tem que lidar com demandas pulsionais, para que estas não provoquem efeitos patogênicos e nem sejam sentidas como dolorosas (FREUD, 1914). E adoecemos devido ao conflito entre as exigências pulsionais e a resistência interna que construímos (FREUD, 1933a). Tais resistências são frutos do trabalho de cultura. Adoecer, aqui, traduz a incapacidade do aparelho psíquico (Seeler Apparat) em lidar com o excesso de patos, com o excesso pulsional, fazendo com que a pulsão se torne inutilizável para o processo civilizatório, incapacitando o indivíduo a dar a sua contribuição para a cultura.

Nesta perspectiva, o perverso seria o indivíduo no qual teria acorrido uma intensa fixação em uma forma exclusiva de satisfação provocando, na vida adulta, a manutenção de uma das faces da polimorfia do sexual infantil. Este indivíduo "permanece pervertido e sofre as consequências do seu desvio dos padrões de civilização" (FREUD, 1908, p. 196). As consequências são as sanções sociais, cuja intensidade varia em função da distância entre o ato considerado perverso e o trabalho que a cultura deveria ter executado. Neste quadro se encaixam as grandes perversões sexuais, ou melhor, as grandes perversões do sexual.

Se "há sem dúvida algo inato na base das perversões, mas esse algo é inato em todos os seres humanos" (FREUD, 1905, p. 174), todos trazemos potencialidades perversas oriundas da polimorfia do sexual infantil que podem se manifestar se a ocasião nos apresentar. Os germes da perversão estão sempre prontos a serem reatualizados trazendo para o primeiro plano o "primitivo do homem": a menor ameaça de perda dos objetos de satisfação produz um 
retorno de moções pulsionais destrutivas. Entretanto, nos lembra Freud, o perverso sexual não é necessariamente perverso em outras áreas da existência (FREUD, 1905). Dai a atenção que devemos ter no sentido de não deslocarmos o ato para o indivíduo, como se eles - os perversos - constituíssem uma categoria a parte, os únicos capazes de praticar determinados atos.

Podemos dizer que o que distingue a perversão nossa de cada dia das grandes perversões do sexual é a relação entre o quantum da força (Drang) da pulsão em busca de satisfação a qualquer preço independentemente do objeto, e o grau de eficácia do trabalho de cultura em coibir a parte da excitação sexual inútil à civilização: "grande parte das forças suscetíveis de utilização em atividades culturais são obtidos pela supressão dos chamados elementos pervertidos da excitação sexual" (FREUD, 1908, 194). Assim, da mesma forma que um sujeito é invadido por um sentimento de estranheza (Das Unheimliche) quando surpreendido por algo que não queria dizer, mas disse, ou não queria fazer, mas fez, o assujeitado a um elevado quantum pulsional responde, igualmente, as exigências da pulsão com uma perversão inaceitável pelo processo civilizatório: nas grandes perversões do sexual, as dinâmicas psíquicas traduzem moções pulsionais tão intensas que o trabalho de cultura mostra-se totalmente ineficaz. Acredito que o elevado fator quantitativo da pulsão seja um dos aspectos que torne a análise das perversões um desafio, que requer uma disposição especial por parte do analista. Este ponto é corroborado por Freud em 1937 em Analise terminável e interminável. Nesse texto de referência sobre a eficácia da análise, Freud nos diz que um fator constitucional muito forte é prejudicial ao sucesso da análise:

Uma força constitucional do instinto [Trieb] e uma alteração desfavorável do ego, adquirida em sua luta defensiva, no sentido de ele ser deslocado e restringido, são os fatores prejudiciais à eficácia da análise e que podem tornar interminável sua duração. (FREUD, 1937, p. 252).

\section{A disposição do analista e a escuta da perversão}

Antes de terminar, gostaria de trazer algumas reflexões sobre a escuta do perverso. Acredito que a analisabilidade do perverso depende do referencial teórico que sustenta a escuta do psicanalista. Ou seja, de como a teoria com a qual o analista trabalha concebe as manifestações às perversões:

A desarmonia entre as diferentes escolas de psicanálise, tanto no uso da palavra "perversão", quanto na apreensão e compreensão do fenômeno é tão conhecida que

\section{POLÊM!CA | Revista Eletronica da verj}


dispensa comentários. Cada modelo clínico propõe uma interpretação diferente direcionando a escuta e, conseqüentemente, a direção do tratamento desta manifestação da sexualidade. Tanto autores da Escola Inglesa, quanto da Americana, relatam acompanhamentos clínicos de sujeitos perversos cujos resultados foram considerados satisfatórios. Já a Escola Francesa de Jacques Lacan entende a perversão como uma estrutura que resiste ao trabalho analítico (CECCARELLI, 2005, p. 47).

Para Freud (1905), sabemos, as perversões são acessíveis ao trabalho analítico, pois ambas são afetadas pelo recalque:

Isto [o bloqueio do fluxo pulsional devido ao recalque] não se aplica apenas às tendências "negativas" para a perversão que aparecem nas neuroses, mas igualmente às perversões chamadas positivas. Assim, estas últimas devem originar-se não apenas de uma fixação de tendências infantis, mas também de uma regressão àquelas tendências como resultado do bloqueio de outros canais da corrente sexual. É por este motivo que as perversões positivas são acessíveis à terapia psicanalítica" (FREUD, 1905, p. 239).

E embora para alguns partidários da escola lacaniana, o perverso não seria analisável, pois, devido ao mecanismo da recusa (Verneinung), ele conseguiria enfrentar aquilo que tenta negar, o Seminário do livro X A angústia (LACAN, 2005), nos apresenta um outro panorama:

\begin{abstract}
Mesmo na perversão, na qual o desejo se dá como aquilo que serve de lei, ou seja,como uma subversão da lei, ele é, efetivamente, suporte de uma lei. Se há uma coisaque hoje sabemos do perverso, é que aquilo que aparece externamente como umasatisfação irrefreada é uma defesa, bem como o exercício de uma lei, na medida emque esta refreia, suspende, detém o sujeito no caminho do gozo. A vontade de gozono perverso, como em qualquer outro, é uma vontade que fracassa que depara comseu próprio limite, seu próprio freio, no exercício mesmo do desejo. (...) $\mathrm{O}$ perverso não sabe a serviço de qual gozo seexerce sua atividade. Mas, em todo caso, não é a serviço da sua. (LACAN,1962-63/2005, p. 166)
\end{abstract}

De qualquer forma, a escuta do perverso exige que o analista acompanhe, na transferência, a reatualização de conflitos psíquicos, e os movimentos regressivos do analisando que o conduzirão aos pontos de fixação libidinal pré-genitais. Quanto ao analista, por não estar ao abrigo de seu sexual recalcado, o risco de deriva para a "perversão do outro lado de divã" não pode ser ignorado, sob pena de transformar a análise em um cenário perverso no qual traumas infantis são atuados em vez de elaborados.

\title{
Referências
}

CECCARELli, P. R. Perversão e suas versões. Reverso, Revista do Círculo Psicanalítico de Minas Gerais, ano XXVII, 52, 43-50, 2005.

\section{POLÊM!CA | Revista Eletronica da Ueji}


Laço social: ilusão contra o desamparo. Reverso, Revista do Círculo Psicanalítico de Minas Gerais, ano XXXI, 58, 33-42, 2009.

. As possíveis leituras das perversões. Estudos de Psicanálise, 36, p. 135-148, Dez./2011.

CECCARELLI, P. R., \& SALLES, A C.. A invenção da sexualidade. Reverso, Revista do Círculo

Psicanalítico de Minas Gerais, ano XXXII, 60, 15-24, 2010.

CECCARELLI, P. R., \& SANTOS, A.B. A produção discursiva no campo da perversão. Polêmica: Revista Eletrônica, v. 9, n. 2, 2010. Disponível em: <http://www.e-

publicacoes.uerj.br/index.php/polemica/article/view/2747>. Acesso em: 4 de maio de 2015.

CHASSEGUET-SMIRGEL, J. Éthique et esthétique de la perversion. Paris: Champ Vallon, 1984.

FOUCAULT, Michel. História da sexualidade I: a vontade de saber. $6^{\text {a }}$ ed. Rio de Janeiro: Edições Graal, 1985.

História da sexualidade II: o uso dos prazeres. Rio de Janeiro: Edições Graal, 1984.

História da sexualidade III: o cuidado de si. Rio de Janeiro: Edições Graal, 1985b.

FREUD, S. Três ensaios sobre a teoria da sexualidade (1905). Edição Standard Brasileira das Obras Completas, Rio de Janeiro: Imago, 1972, Vol. VII.

Moral sexual civilizada e doença nervosa moderna (1908). Edição Standard Brasileira das Obras Completas. Rio de Janeiro: Imago, 1976, Vol. VIII. Vol. XIII.

Totem e Tabu (1913). Edição Standard Brasileira das Obras Completas. Rio de Janeiro: Imago, 1974,

Neuroses de transferência: uma síntese (1915a). Rio de Janeiro: Imago, 1987.

Reflexões para os tempos de guerra e morte (1915b). Edição Standard Brasileira das Obras Completas. Rio de Janeiro: Imago, 1976, Vol. XIV.

As pulsões e seus destinos (1915c). Edição Standard Brasileira das Obras Completas. Rio de Janeiro: Imago, 1976, Vol. XIV.

O desenvolvimento da libido e as organizações sexuais (1917). Edição Standard Brasileira das Obras Completas. Rio de Janeiro: Imago, 1976, Vol. XVI.

Além do princípio do prazer (1920). Edição Standard Brasileira das Obras Completas. Rio de Janeiro: Imago, 1976, Vol. VIII.

O mal-estar na civilização (1930). Edição Standard Brasileira das Obras Completas. Rio de Janeiro: Imago, 1974, Vol. XXI.

A dissecação da personalidade psíquica (1933a). Edição Standard Brasileira das Obras Completas. Rio de Janeiro: Imago, 1976, Vol. XXII.

A questão de uma Weltanschauung (1933b). Edição Standard Brasileira das Obras Completas. Rio de Janeiro: Imago, 1976, Vol. XXII.

Por que a guerra? (1933c). Edição Standard Brasileira das Obras Completas. Rio de Janeiro: Imago, 1976, Vol. XXII.

\section{POLÊM!CA | Revista Eletrônica da Uerj}

Rua São Francisco Xavier, 524, $2^{\circ}$ andar - BL D, sl 2025 - Maracanã

Tels.: +55 $212334-0888 / 0887$

http://www.labore.uerj.br/ - laboreuerj@yahoo.com.br 
Esboço de Psicanálise - A teoria dos instintos (1938). Edição Standard Brasileira das Obras Completas. Rio de Janeiro: Imago, 1975, Vol. XXIII.

Análise Terminável e Interminável (1937). Edição Standard Brasileira das Obras Completas. Rio de Janeiro: Imago, 1972, Vol., XXIII.

MASSON, J. A correspondência completa Freud-Fliess, 1887-1904. Rio de Janeiro: Imago, 1986.

LACAN, J. Le séminaire du livre X: L'angoisse. Paris: Seuil, 2004.

ROUDINESCO, E. La part obscure de nous-mêmes: Une histoire des pervers. Paris: Albin Michel, 2007.

Recebido em: 15/04/2015.

Aceito em: 11/05/2015. 